\title{
Effects of hypoxia on serum hepatic chemistries of Tibet chicken and Shouguang chicken
}

\author{
Wenpeng Han ${ }^{1 \#}$, Meiling Song ${ }^{1,2 \#}$, Hui Yuan ${ }^{1 \#}$, Haigang Bao ${ }^{1}$, Chong Liu ${ }^{3}$, Changxin Wu ${ }^{1}$ and \\ Chunjiang Zhao ${ }^{1^{*}}$ \\ ${ }^{1}$ College of Animal Science and Technology, China Agricultural University, Beijing 100193, China. \\ ${ }^{2}$ Dongying technician college, Shandong, 257091, China. \\ ${ }^{3}$ Institute of Environment and Sustainable Development in Agriculture, Chinese Academy of Agricultural Sciences, \\ Beijing 100081, China.
}

Accepted 26 June, 2013

\begin{abstract}
Hypoxia is a major factor that affects the subsistence and development of multicellular organisms. Tibet chicken, as a unique native chicken breed in altiplano, shows genetic adaptation to hypoxia comparing with the breeds at the low altitude. In the present study, to explore effects of hypoxia on chicken fetal livers, eggs of Tibet chicken and Shouguang chicken were collected and the samples from each breed were divided into two groups, incubated in hypoxia and in normoxia respectively. The blood of embryos on the 16th day of incubation was collected and the serum chemistry parameters indicating liver metabolism were determined, which included glutamic-pyruvic transaminase (GPT), aspartate aminotransferase (GOT), total bilirubin (TB), direct bilirubin (DB), total bile acid (TBA), gamma glutamyltransferase (GGT), alkaline phosphatease (ALP), lactate dehydrogenase (LDH), creatine kinase (CK), glucose and creatinine. The results show that biochemical indices varied significantly between hypoxia and normoxia except for GPT and glucose. Moreover, the concentration of ALP and LDH showed significant differences between the breeds and the incubations. The results suggest that the livers of both Shouguang chicken and Tibet chicken suffered damages in hypoxia, but the former was more serious. The results of this study support the opinion that Tibet chicken had better genetic adaptability on hypoxia, and made a good basis for further study of the genetic mechanism of adaptation to hypoxia.
\end{abstract}

Key words: Hypoxia adaptation, liver metabolism, serum chemistry, Tibet chicken, chicken embryo.

\section{INTRODUCTION}

Hypoxia is a major causative factor of diseases in altiplano, which influences seriously the subsistence and development of multicellular organisms, such as plants, animals, and human beings (Heacock and Sutherland,
1990; Archer et al., 2004). Previous studies have shown that chronic intermittent hypoxia can lead to liver injury and nonalcoholic fatty liver disease, via oxidative stress and excessive glycogen accumulation, and then resulted)

*Corresponding author. E-mail: cjzhao@cau.edu.cn. Tel: +86-10-62894888.

\#These authors contributed equally to this work.

Abbreviation: GPT, Glutamic-pyruvic transaminase; GOT, aspartate aminotransferase; TB, total bilirubin; DB, direct bilirubin; TBA, total bile acid; GGT, gamma glutamyltransferase; ALP, alkaline phosphatease; LDH, lactate dehydrogenase, CK, creatine kinase. 
Table 1. Serum chemistry parameters in Shouguang Chicken and Tibet Chicken under different incubation conditions.

\begin{tabular}{lcccc}
\hline \multirow{2}{*}{ Serum component } & \multicolumn{2}{c}{ Shouguang Chicken } & \multicolumn{2}{c}{ Tibet Chicken } \\
\cline { 2 - 5 } & Normoxia & Hypoxia & Normoxia & Hypoxia \\
\hline GPT (IU/L) & $3.26 \pm 0.41^{\mathrm{a}}$ & $3.84 \pm 0.69^{\mathrm{a}}$ & $3.67 \pm 0.36^{\mathrm{a}}$ & $4.22 \pm 0.35^{\mathrm{a}}$ \\
GOT (IU/L) & $21.83 \pm 0.35^{\mathrm{a}}$ & $27.66 \pm 5.61^{\mathrm{b}}$ & $18.61 \pm 0.73^{\mathrm{a}}$ & $18.84 \pm 1.46^{\mathrm{a}}$ \\
TB (umol/L) & $10.38 \pm 0.25^{\mathrm{a}}$ & $16.34 \pm 0.35^{\mathrm{b}}$ & $15.26 \pm 0.35^{\mathrm{b}}$ & $13.1 \pm 0.31 \mathrm{c}$ \\
DB (umol/L) & $0.56 \pm 0.026^{\mathrm{a}}$ & $0.92 \pm 0.047^{\mathrm{b}}$ & $0.80 \pm 0.042^{\mathrm{b}}$ & $0.66 \pm 0.032^{\mathrm{b}}$ \\
TBA (umol/L) & $0.66 \pm 0.036^{\mathrm{a}}$ & $1.14 \pm 0.036^{\mathrm{b}}$ & $0.60 \pm 0.050^{\mathrm{a}}$ & $0.86 \pm 0.028^{\mathrm{c}}$ \\
ALP (IU/L) & $622.83 \pm 6.66^{\mathrm{a}}$ & $1244.65 \pm 10.92^{\mathrm{b}}$ & $806.09 \pm 7.27^{\mathrm{c}}$ & $1011.13 \pm 10.37^{\mathrm{d}}$ \\
GGT (IU/L) & $1.21 \pm 0.14^{\mathrm{b}}$ & $1.82 \pm 0.14^{\mathrm{a}}$ & $1.44 \pm 0.17^{\mathrm{b}}$ & $1.86 \pm 0.14^{\mathrm{a}}$ \\
CK (IU/L) & $106.11 \pm 5.15^{\mathrm{b}}$ & $119.60 \pm 5.92^{\mathrm{a}}$ & $129.64 \pm 8.05^{\mathrm{a}}$ & $116.22 \pm 4.75^{\mathrm{a}}$ \\
Glucose (umol/L) & $5.44 \pm 0.060^{\mathrm{a}}$ & $5.27 \pm 0.052^{\mathrm{a}}$ & $5.77 \pm 0.061^{\mathrm{a}}$ & $5.39 \pm 0.047^{\mathrm{a}}$ \\
Creatinine (umol/L) & $1.12 \pm 0.29^{\mathrm{a}}$ & $4.73 \pm 0.31^{\mathrm{b}}$ & $1.70 \pm 0.097^{\mathrm{a}}$ & $5.54 \pm 0.044^{\mathrm{b}}$ \\
LDH (IU/L) & $207.20 \pm 4.54^{\mathrm{a}}$ & $394.61 \pm 4.55^{\mathrm{b}}$ & $199.83 \pm 7.27^{\mathrm{c}}$ & $237.84 \pm 7.92^{\mathrm{d}}$ \\
\hline
\end{tabular}

Values in the same row with different letters means that the difference between them is significant difference $(p<0.05)$.

changes on levels of some serum content including glutamic-pyruvic transaminase (GPT), aspartate aminotransferase (GOT), bilirubin, gamma glutamyltransferase (GGT), alkaline phosphatease (ALP) (Puhl et al., 2005; Tanne et al., 2005; Savransky et al., 2007a, b, 2009). Therefore, the determination of those enzymes and substances was performed to evaluate the potential pathological changes of organisms (Nakamura et al, 2008).

In this study, we employed Tibet Chicken, a unique native chicken breed inhabiting in Tibet altiplano with an average altitude above $3000 \mathrm{~m}$, and aimed to study the changes of fetal liver in hypoxia by determining the serum chemistry, compared with Shouguang chicken, an indigenous Chinese chicken breed in Shouguang county of Shandong province with an altitude less than $100 \mathrm{~m}$, to explore the change patterns of the serum hepatic chemistry of the two chicken breeds in hypoxia.

\section{MATERIALS AND METHODS}

\section{Animals and sampling procedures}

The fertile eggs of each breeds, Tibet chicken and Shouguang chicken, from the experiment chicken farm of the China Agricultural University (CAU, Beijing, 100m altitude) were divided into two groups, and exposed to sustained normal oxygen partial pressure $\left(21 \% \mathrm{O}_{2}\right)$ and hypoxia $\left(13 \% \mathrm{O}_{2}\right)$ with the same other incubation conditions (such as $37.8^{\circ} \mathrm{C}, 60 \%$ relative humidity and so on) respectively, after the eggs and the incubators were sterilized. On the 16th day of incubation, the eggshells were broken at the air-cell and then the blood was taken using injector treated with heparin sodium from the thickest artery on the chorioallantoic membrane pulled out. Serum separated from blood samples after centrifuged at $1000 \mathrm{~g}$ for $10 \mathrm{~min}$. Ten (10) blood samples were collected from each studied group to be analyzed separately and totally 40 samples were determined in the present study.

\section{Determination of serum chemistry parameters}

The serum chemistry assays were determined using automatic biochemistry analyzer (Hitachi 7 600, Hitachi, Japan) in the 309 Hospital in Beijing, and performed in terms of glutamic-pyruvic transaminase (GPT), aspartate aminotransferase (GOT), total bilirubin (TB), direct bilirubin (DB), total bile acid (TBA), gamma glutamyltransferase (GGT), alkaline phosphatease (ALP), lactate dehydrogenase (LDH), creatine kinase (CK), glucose, and creatinine.

\section{Statistical analysis}

Data of this study were subjected to variance analysis using SAS software (Version 8.02, SAS Inc, US), and the significant level was fixed to $p<0.05$ and extreme significance $p<0.01$. The model using to analyze the data was:

$Y_{i j k}=\mu+\alpha_{i}+\beta_{j}+(\alpha \beta)_{i j}+\varepsilon_{i j k}$

Where, $Y_{i j k}$, is the parameter of serum hepatic chemistries of embryo $k$ from breed $i$ and incubation condition $j ; \mu$, is the overall mean; $\alpha_{i}$ is the main effect of breed $i(\mathrm{n}=2) ; \beta_{i}$, is the main effect of incubation condition $j(\mathrm{n}=2) ;(\alpha \beta)_{i j}$, is the interaction between breed and incubation condition; and $\varepsilon_{i j k}$, is the random error term. Values were shown as mean and standard error.

\section{RESULTS AND DISCUSSION}

The purpose of the study was to investigate the changes in serum hepatic biochemistry of Tibet Chicken and Shouguang Chicken incubated in hypoxia, and the results are shown in Table 1.

Liver injury, which led to the elevations of serum chemistries such as GPT, GOT, ALP, has been demonstrated in hypoxia in many studies (Tanne et al., 2005; Savransky et al., 2007a, b, 2009). The reports of the effects in chronic intermittent hypoxia showed that chronic 
liver injury and nonalcoholic fatty liver disease included isolated fatty liver, nonalcoholic steatohepatitis, fibrosis and liver cirrhosis (Tanne et al., 2005; Kallwitz et al., 2007; Mishra et al., 2008; Norman et al., 2008). However, the levels of these enzymes can be elevated in a variety of liver injury (Savransky et al., 2007a, b, 2009). Previous studies interpreted that both hypoxia alone and cooperating with other factors can lead to the changes of serum hepatic chemistries, but the changes were not all coincident. The ratio of GOT to GPT was sometimes used in clinical diagnosis of hepatic disorders (Kang, et al, 2013). Different ratios were present in a variety of hepatic disorders, and mostly the ratio of GOT/GPT greater than 2 was present in alcoholic hepatitis and some other disorders such as Wilson's disease (Sorbi et al., 1999; Giannini et al., 2003). The GPT in the present study, which was considered to be more specific for hepatic injury because it exists mainly in the cytosol of the liver and in low concentrations elsewhere (Giboney, 2005), was not significantly changed, but the ratios of GOT/GPT (27.6 $\pm 5.6064 \quad \mathrm{IU} / \mathrm{L}(\mathrm{GOT}), \quad 3.8 \pm 0.6855 \mathrm{IU} / \mathrm{L}$ (GPT) in Shouguang Chicken and 18.8 $\pm 1.4560 \mathrm{IU} / \mathrm{L}$ (GOT), $4.2 \pm 0.3464 \mathrm{IU} / \mathrm{L}(\mathrm{GPT})$ in Tibet chicken, respectively) were more than 2-fold in hypoxia in our work, which indicated that the fetal livers of both Shouguang chicken and Tibet chicken were injured in hypoxia and Shouguang chicken suffered more serious damages. However, ratio utility had significant limitations. Except for the hepatic disorders, some evidences showed sexrelated differences and physiological changes in metabolism of avian can also induce the elevations of GOT, GPT and bilirubin (Walzem et al., 1999; Scholtz et al., 2009).

In this study, ALP and LDH showed dramatic changes between the breeds and the incubations. Though both of them are less specific than GPT and GOT in diagnosis of hepatic disorders, they were sometimes employed to provide further evidences about the patterns of liver injury (Musana et al., 2004; Shokrzadeh, et al, 2012). Elevation of ALP in serum were derived from the liver and bone predominantly during the third trimester of pregnancy of women and the rapidly growth of adolescents (Wolf, 1978; Pratt and Kaplan, 2000). Therefore, the elevation of ALP in this study may be due to both liver injury and embryonic growth predominantly, which should be verified by other parameters because the damages of kidney, intestine and placenta also elevate the level of ALP slightly. While in hypoxia, the elevation of LDH may be that, there was not enough oxygen to meet the need of organism due to the lack of red blood cells in blood (Garba and Ubom, 2005; Macedo et al., 2009), or the organs of metabolism and respiration were damaged (Granchi et al., 2010), and the expression of both LDH-A mRNA and protein were inducible by hypoxia (Robin et al., 1984; Marti et al., 1994; Firth et al., 1994, 1995). Several other evidences in which the production of LDH increases in hypoxia support this point (Rees et al., 2001;
Koukourakis et al., 2006). In addition, the ratio of GPT/LDH was also used in diagnosis of liver disorders (Kotoh et al., 2008; Balasubramanian et al., 2010). In this study, both ALP and LDH have shown significant differences between the breeds and the incubations, and the changes of Shouguang chicken in hypoxia was greater than that of Tibet chicken, which may suggest that Tibet chicken has a better adaptability to the changes of oxygen partial pressure. But the various trends of other parameters may be due to the decrease of the metabolic levels of Tibet chicken in hypoxia or the limited samples in our study.

In conclusion, our results suggested that though the liver metabolism of both chicken breeds was affected negatively by hypoxia, Tibet chicken suffered less damage than Shouguang chicken in hypoxia. So our study supported the opinion that Tibet chicken has better genetic adaptability in hypoxia.

\section{ACKNOWLEDGEMENTS}

This research was supported by the National Program on Key Basic Research Project (Grant No. 2006CB102101) of China.

\section{REFERENCES}

Archer SL, Wu XC, Thebaud B, Moudgil R, Hashimoto K, Michelakis E $\mathrm{D}$ (2004). $\mathrm{O}_{2}$ sensing in the human ductus arteriosus: Redox sensitive $\mathrm{K}+$ channels are regulated by mitochondria-derived hydrogen peroxide. Biol. Chem. 385(3-4):205-216.

Balasubramanian S, Kaarthigeyan K, Srinivas S, Rajeswari R (2010). Serum ALT: LDH ratio in typhoid fever and acute viral hepatitis. Indian Pediatr. 47 (4):339-341.

Firth JD, Ebert BL, Pugh CW, Ratcliffe PJ (1994). Oxygen-regulated control elements in the phosphoglycerate kinase 1 and lactate dehydrogenase A genes: similarities with the erythropoietin 3' enhancer. Proc. Natl. Acad. Sci. USA. 91(14):6496-6500.

Firth JD, Ebert BL, Ratcliffe PJ (1995). Hypoxic regulation of lactate dehydrogenase A: Interaction between hypoxia-inducible factor 1 and cAMP response elements. J. Biol. Chem. 270(36):21021-21027.

Garba IH, Ubom GA (2005). Total serum lactate dehydrogenase activity in acute plasmodium falciparum malaria infection. Singapore Med. J. 46(11):632-634.

Giannini E, Risso D, Botta F, Chiarbonello B, Fasoli A, Malfatti F, Romagnoli P, Testa E, Ceppa P, Testa R (2003). Validity and clinical utility of the aspartate aminotransferase-alanine aminotransferase ratio in assessing disease severity and prognosis in patients with hepatitis $C$ virus-related chronic liver disease. Arch. Intern. Med. 163 (2):218-224.

Giboney PT (2005). Mildly elevated liver transaminase levels in the asymptomatic patient. Review. Am. Fam. Physician 71(6):1105-1110.

Granchi C, Bertini S, Macchia M, Minutolo F (2010). Inhibitors of lactate dehydrogenase isoforms and their therapeutic potentials. Curr. Med. Chem. 17(7):672-697.

Heacock CS, Sutherland RM (1990). Enhanced synthesis of stress proteins caused by hypoxia and relation to altered cell growth and metabolism. Br. J. Cancer 62(2):217-225.

Kallwitz ER, Herdegen J, Madura J, Jakate S, Cotter SJ (2007). Liver enzymes and histology in obese patients with obstructive sleep apnea. J. Clin. Gastroenterol. 41(10):918-921.

Kang MC, Kang SM, Ahn G, Kim KN, Kang N, Samarakoon KW, Oh 
MC, Lee JS, Jeon YJ (2013). Protective effect of a marine polyphenol, dieckol against carbon tetrachloride-induced acute liver damage in mouse. Environ Toxicol Pharmacol. 35(3):517-523.

Kotoh K, Enjoji M, Kato M, Kohjima M, Nakamuta M, Takayanagi R (2008). A new parameter using serum lactate dehydrogenase and alanine aminotransferase level is useful for predicting the prognosis of patients at an early stage of acute liver injury: a retrospective study. Comp. Hepatol. 7:6

Koukourakis M I, Pitiakoudis M, Giatromanolaki A, Tsarouha A, Polychronidis A, Sivridis E, Simopoulos C (2006). Oxygen and glucose consumption in gastrointestinal adenocarcinomas: correlation with markers of hypoxia, acidity and anaerobic glycolysis. Cancer Sci. 97(10):1056-1060.

Macedo DV, Lazarim FL, Catanho da Silva FO, Tessuti LS, Hohl R (2009). Is lactate production related to muscular fatigue? A pedagogical proposition using empirical facts. Adv. Physiol. Educ. 33(4):302-307.

Marti HH, Jung HH, Pfeilschifter J, Bauer C (1994). Hypoxia and cobalt stimulate lactate dehydrogenase (LDH) activity in vascular smooth muscle cells. Pflugers Arch. 429(2):216-222.

Mishra $\mathrm{P}$, Nugent $\mathrm{C}$, Afendy A, Bai C, Bhatia P, Afendy M, Fang $\mathrm{Y}$, Elariny H, Goodman Z, Younossi ZM (2008). Apnoeic-hypopnoeic episodes during obstructive sleep apnea are associated with histological nonalcoholic steatohepatitis. Liver Int. 28 (8):1080-1086.

Musana KA, Yale SH, Abdulkarim AS (2004). Tests of liver injury. Clin. Med. Res. 2 (2):129-131.

Nakamura M, Sato S, Shimamoto T, Konishi M, Yoshiike N (2008). Establishment of long-term monitoring system for blood chemistry data by the national health and nutrition survey in Japan. $J$. Atheroscler. Thromb. 15(5):244-249.

Norman D, Bardwell WA, Arosemena F, Nelesen R, Mills PJ, Loredo J S, Lavine JE, Dimsdale JE (2008). Serum aminotransferase levels are associated with markers of hypoxia in patients with obstructive sleep apnea. Sleep 31(1):121-126.

Pratt DS, Kaplan MM (2000). Evaluation of abnormal liver-enzyme results in asymptomatic patients. N. Engl. J. Med. 342:1266-1271.

Puhl G, Schaser KD, Pust D, Kohler K, Vollmar B, Menger MD, Neuhaus P. Settmacher U (2005). Initial hepatic microcirculation correlates with early graft function in human orthotopic liver transplantation. Liver Transpl. 11(5):555-563.

Rees BB, Bowman JA, Schulte PM (2001). Structure and sequence conservation of a putative hypoxia response element in the lactate dehydrogenase-B gene of Fundulus. Biol. Bull. 200 (3):247-251.
Robin ED, Murrhpy BJ, Theodore J (1984). Coordinate regulation of glycolysis by hypoxia in mammalian cells. J. Cell Physiol. 118(3):287290.

Savransky V, Bevans S, Nanayakkara A, Li J, Smith PL, Torbenson MS, Polotsky VY (2007b). Chronic intermittent hypoxia causes hepatitis in a mouse model of diet-induced fatty liver. Am. J. Physiol. Gastrointest. Liver Physiol. 293(4):G871-877.

Savransky V, Nanayakkara A, Vivero A, Li J, Bevans S, Smith PL, Torbenson MS, Polotsky VY (2007a). Chronic intermittent hypoxia predisposes to liver injury. Hepatology. 45(4):1007-1013.

Savransky V, Reinke C, Jun J, Bevans-Fonti S, Navayakkara A, Li J, Myers A C, Torbenson M S, Polotsky V Y. (2009). Chronic intermittent hypoxia and acetaminophen induce synergistic liver injury. Exp Physiol. 94(2):228-239.

Scholtz N, Halle I, Flachowsky G, Sauerwein H (2009). Serum chemistry reference values in adult Japanese quail (Coturnix coturnix japonica) including sex-related differences. Poult. Sci. 88(6):11861190.

Shokrzadeh M, Shobi S, Attar H, Shayegan S, Payam SS, Ghorbani F (2012). Effect of vitamins A, E and C on liver enzyme activity in rats exposed to organophosphate pesticide diazinon. Pak J Biol Sci. 15(19):936-941.

Sorbi D, Boynton J, Lindor KD (1999). The ratio of aspartate aminotransferase to alanine aminotransferase: potential value in differentiating nonalcoholic steatohepatitis from alcoholic iver disease. Am. J. Gastroenterol. 94 (4):1018-1022.

Tanne F, Gagnadoux F, Chazouilleres O, Fleury B, Wendum D, Lasnier E (2005). Chronic liver injury during obstructive sleep apnea. Hepatology 41(6):1290-1296.

Walzem RL, Hansen RJ, Williams DL, Hamilton RL (1999). Estrogen induction of VLDLy assembly in egg-laying hens. J. Nutr. 129 (2S Suppl):467S-472S.

Wolf PL (1978). Clinical significance of an increased or decreased serum alkaline phosphatase level. Arch. Pathol. Lab. Med. 102 (10): 497-501. 